\title{
Evaluating the predictability of distance race performance in NCAA cross country and track and field from high school race times in the United States
}

\author{
Authors: Jamie L. Brusa
}

This is an Accepted Manuscript of an article published in Journal of Sports Sciences on December 30, 2017, available online: http://

www.tandfonline.com/10.1080/02640414.2017.1422420

Brusa, Jamie L. . "Evaluating the predictability of distance race performance in NCAA cross country and track and field from high school race times in the United States." Journal of Sports Sciences (December 2017): 1-8. DOI: 10.1080/02640414.2017.1422420.

Made available through Montana State University's ScholarWorks scholarworks.montana.edu 


\title{
Evaluating the predictability of distance race performance in NCAA cross country and track and field from high school race times in the United States
}

\author{
Jamie L. Brusa \\ Department of Ecology, Montana State University, Bozeman, MT, USA
}

\begin{abstract}
Successful recruiting for collegiate track \& field athletes has become a more competitive and essential component of coaching. This study aims to determine the relationship between race performances of distance runners at the United States high school and National Collegiate Athletic Association (NCAA) levels. Conditional inference classification tree models were built and analysed to predict the probability that runners would qualify for the NCAA Division I National Cross Country Meet and/or the East or West NCAA Division I Outdoor Track \& Field Preliminary Round based on their high school race times in the $800 \mathrm{~m}, 1600 \mathrm{~m}$, and $3200 \mathrm{~m}$. Prediction accuracies of the classification trees ranged from 60.0 to 76.6 percent. The models produced the most reliable estimates for predicting qualifiers in cross country, the $1500 \mathrm{~m}$, and the $800 \mathrm{~m}$ for females and cross country, the $5000 \mathrm{~m}$, and the $800 \mathrm{~m}$ for males. NCAA track $\&$ field coaches can use the results from this study as a guideline for recruiting decisions. Additionally, future studies can apply the methodological foundations of this research to predicting race performances set at different metrics, such as national meets in other countries or Olympic qualifications, from previous race data.
\end{abstract}

\section{Introduction}

In the United States (U.S.), coaches at the National Collegiate Athletic Association (NCAA) Division I level rely on recruiting efforts to either maintain or improve the competitive ability of their teams. As collegiate athletes graduate and complete their NCAA eligibilities, new athletes, often in the form of high school seniors, are recruited to the team to begin competing the following season. Recruiting talented prospective student-athletes has become increasingly important for successful athletic programmes (Langelett, 2003), and coaching retention in the NCAA depends on the performance of the athletes relative to expectations (Humphreys, Paul, \& Weinbach, 2016; Treadway et al., 2012). Thus, NCAA coaches have strong motivation to recruit skilled athletes. Better performing teams attract significantly more talented recruits than those with less impressive records, and recruiting can account for up to $80 \%$ of the performance of a team in American football (Caro, 2012; Langelett, 2003).

Evaluating the relationship between competitive athletic performance in recruits at the high school and NCAA levels remains a research topic that has received little attention, especially in individual sports. Given this limited research, NCAA coaches often assume that athletic prowess at the high school level will continue at the NCAA level. However, assuming adolescent competitive performance translates to adult competitive performance can be littered with problems (Vaeyens, Güllich, Warr, \& Philippaerts, 2009). For example, multiple studies have demonstrated that several competent junior elite athletes either do not advance to or are not as competitive at the senior elite level in distance running (Bussman \& Alfermann, 1994), soccer, judo, swimming, and volleyball (Barreiros, Côté, \& Fonesca, 2014).

Many NCAA cross country/track \& field coaches seek to recruit athletes who will qualify for the NCAA Division I National Cross Country Meet and/or in the East or West NCAA Division I Outdoor Track \& Field Preliminary Round. In recent years, NCAA cross country/track \& field coaches have gained access to race results via the internet. While direct observation of an athlete provides additional insight into competitive athletic performance, the university racing schedule, NCAA limitations on the number of evaluations (i.e., direct observations) a coach can conduct for each athlete (2014-2015 NCAA Division I Manual, Bylaw 13.1.7.2.1), and budgetary restrictions (Kelly \& Baghurst, 2009) can limit the number of direct observations. Given these restrictions, coaches must strategically choose which high school races to attend to further evaluate runners.

Limited roster spots and scholarship offers further raise the stakes of recruiting. Many NCAA Division I track \& field teams post on their websites their minimum marks required for runners to either join the team as a "walk-on" or be eligible for an athletic scholarship. However, these minimum marks might exclude runners who will perform well at the NCAA level despite their less competitive high school times. Quantitative information regarding the relationship between race performance at the high school and NCAA levels can lead to better precision for these minimum marks. The NCAA limits each Division I track \& field team to 18 scholarships for women and 12.6 scholarships for men for coaches to distribute among 
cross country/track \& field athletes as they see fit (2014-2015 NCAA Division I Manual, Bylaw 15.02.4.2). Considering the limited number of scholarships coupled with large roster requirements to fill entries for 21 events in track \& field and seven scoring runners in cross country, investing scholarship money into a track \& field athlete can involve considerable risk.

The objectives of this study were to 1) develop models to quantify the likelihood that a male or female runner will qualify to the NCAA Division I National Cross Country meet and/or the East/West NCAA Outdoor Track \& Field Division I Preliminary Round based on U.S. high school times in the $800 \mathrm{~m}, 1600 \mathrm{~m}$, and $3200 \mathrm{~m}$ races, 2) identify which of these three U.S. high school race distances are most important in predicting NCAA race performance in cross country, the

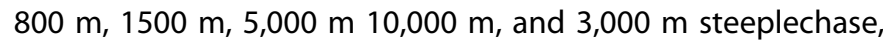
3) compare these predictive models between males and females, and 4) present classification tree-based model building methods that can be broadly applied to other research questions addressing race performance prediction.

\section{Methods}

\section{Data collection}

Predictor variables included the fastest time each athlete ran in the $800 \mathrm{~m}, 1600 \mathrm{~m}$, and $3200 \mathrm{~m}$ at any time throughout his or her high school career. Response variables included whether or not the athlete qualified for the NCAA Division I National Cross Country Meet or the East or West NCAA Division I Outdoor Track \& Field Preliminary Round at any time throughout his/her NCAA career. To qualify for the East/ West NCAA Division I Outdoor Track \& Field Preliminary Round, the season best time for an athlete must rank among the top 48 times for his/her event at the closure of the NCAA non-championship outdoor track \& field season. If an athlete does not declare his/her intent to run an event (commonly occurs if an athlete becomes injured or has qualified in multiple events and does not plan to run each event), the next athlete on the list will then qualify until the event has 48 qualifiers who plan to compete. For the purpose of this study, the top 48 athletes for the $800 \mathrm{~m}, 1500 \mathrm{~m}, 5000 \mathrm{~m}$, $10,000 \mathrm{~m}$, and $3000 \mathrm{~m}$ Steeplechase in the East Division and West Division were coded as qualified. Therefore, any athlete who ranked worse than 48th place was coded as a nonqualifier for this study even if he/she moved into a qualifying spot after better-ranked athletes did not declare intent to race the event.

Race data were compiled from official online results databases: NCAA.com, trackandfieldnews.com, tffrs.org, and milesplit.com. While these websites might have excluded a few race results, the aforementioned websites seem comprehensive and have been used in other studies (Deaner, 2006; Depken \& Haglund, 2011). The top 800 male and female U.S. high school results from 2001 through 2015 for the $800 \mathrm{~m}$, $1600 \mathrm{~m}$, and $3200 \mathrm{~m}$ were compiled. For some U.S. states, high school athletes race the $1500 \mathrm{~m}$ and $3000 \mathrm{~m}$ instead of the $1600 \mathrm{~m}$ and $3200 \mathrm{~m}$. As provided by milesplit.com, $1500 \mathrm{~m}$ times were multiplied by $1.066 \mathrm{~s}$ to convert to $1600 \mathrm{~m}$ times, and $3000 \mathrm{~m}$ times were multiplied by $1.067 \mathrm{~s}$ to convert to $3200 \mathrm{~m}$ times for these athletes. Certain years ( $n=4$ years) provided high school results for fewer than 800 individuals, and as many individuals as possible were included for those years. To analyse the relationship between high school and NCAA cross country race performance, race results from the NCAA Division I National Cross Country Championships from 2004 through 2016 were compiled. This dataset was pared down to include only individuals who competed both in track \& field at a U.S. high school from 2001 through 2016 and cross country at an NCAA Division I university from 2004 through $2015\left(n_{\text {females }}=8692, n_{\text {males }}=9006\right)$. To analyse the relationship between high school and NCAA outdoor track \& field race performance, the top 500 male and female NCAA Division I outdoor track \& field results from 2010 through 2016 for the $800 \mathrm{~m}, 1500 \mathrm{~m}, 5000 \mathrm{~m}$, 10,000 m, and $3000 \mathrm{~m}$ Steeplechase were compiled. This dataset was pared down to include only individuals who competed both in track \& field at a U.S. high school from 2006 through 2015 and track \& field at an NCAA Division I university from 2010 through 2016 ( $n_{\text {females }}=7766$, $n_{\text {males }}=7608$ ). Reliable data for these races prior to 2010 were not available because prior to 2010, the East/West NCAA Outdoor Track \& Field Division I Preliminary Round was instead four regional meets with different qualification standards. Comprehensive lists of the top times in the East and West do not exist prior to 2010.

\section{Data analysis}

Data were analysed using conditional inference classification trees, a type of machine learning model (Hothorn, Hornik, \& Zeileis, 2006). Classification trees can handle datasets with several missing values and require non-parametric analytical tests, enable cross-validation methods for model selection, and are easy to interpret (De'ath \& Fabricius, 2000), rendering them an ideal tool for this study. Conditional inference classification trees use recursive binary partitioning algorithms with piecewise constant fits to eliminate the bias that often accompanies other methods of recursive binary partitioning by incorporating permutation-based significance testing. This permutation-based significance testing is employed at each node (split in the tree) to test the null hypothesis that all predictor variables are independent of the response variable. If the null hypothesis can be rejected, the data are split based on a threshold in the predictor variable that describes most of the variation. This process continues until no further splits can be made (Hothorn et al., 2006). All analyses were performed using $\mathrm{R}$ version 3.3.1 ( $\mathrm{R}$ Core Team, 2016). Classification trees were constructed for each response variable using the ctree function (Hothorn et al., 2006) of the R package, Partykit (Hothorn \& Zeileis, 2015). Additional classification trees were constructed for each NCAA outdoor track \& field distance race using only one predictor variable at a time (e.g., one $1500 \mathrm{~m}$ classification tree constructed using only the $800 \mathrm{~m}$ as the predictor variable, a second $1500 \mathrm{~m}$ classification tree constructed using only the $1600 \mathrm{~m}$ as the predictor variable, and a third using only the $3200 \mathrm{~m}$ as the predictor variable). Restricting these trees to one predictor variable at a time enabled the $\mathrm{R}$ package to return a tree displaying discrete 
groups of times, each with their own associated likelihoods of an athlete qualifying for the NCAA Outdoor Track \& Field Division I Preliminary Round.

To assess tree accuracy, data were randomly partitioned into training and test sets, and a threefold cross validation technique was used in the R package, Caret (Kuhn, 2016). $K$-fold cross validation tests the predictive power of a model by randomly splitting the dataset into $k$ subsets and using $k-$ 1 subsets as the training dataset to construct the model and the remaining subset to test model accuracy. This process repeats until all subsets have been used as the test dataset (Geisser, 1975; Stone, 1974). Balanced accuracy accounts for imbalanced data by applying a penalty for having high accuracy mainly because there is a greater chance of correctly classifying to the highly represented class (Brodersen, Ong, Stephan, \& Buhmann, 2010). In this study, correctly predicting an athlete to not qualify for the NCAA Division I National Cross Country meet and/or the East/West NCAA Outdoor Track \& Field Division I Preliminary Round was easier for the model achieve because only $21.4 \%$ of the females and $22.1 \%$ of the males in the dataset qualified to at least one of the meets. Thus, balanced accuracy was an important adjustment to avoid accuracy inflation (García, Mollineda, \& Sánchez, 2009). Cohen's Kappa scores (K), which also account for imbalances in the data, were also calculated to measure tree accuracy. Strength of agreement labels associated with $\mathrm{k}$ values are: < 0.00 - poor, $0.00-0.20$ - slight, $0.21-0.40$ - fair, 0.41-0.60 moderate, $0.61-0.80$ - substantial, and 0.81-1.00 - almost perfect (Landis \& Koch, 1977).

The relative importance of predictor variables for each model was assessed using a random forest model. Random forests employ ensemble methods by constructing several classification trees, each from a bootstrap sample from the dataset using a random subset of the predictor variables, which can elucidate variables that were important but masked by the highest-ranking predictor variable in the tree model (Strobl, Boulesteix, Zeileis, \& Hothorn, 2007). Random forest models were constructed using the cforest function in the $\mathrm{R}$ package, Party (Strobl et al., 2007). The cforest function constructed 500 trees of varying sizes to determine which variables were used most often in the trees to return a measure of the relative importance of each variable (Meinhausen, 2006).

\section{Results}

The mean times of the 48th best runner in the East and West Divisions from 2010 through 2016 for each distance event are summarised in Table 1. Times were similar between the East and West Divisions as well as across years. After standardising for differences in the amount of time to run each distance, women's $3000 \mathrm{~m}$ steeplechase and men's $800 \mathrm{~m}$ had the greatest variability in qualifying times among the seven years represented in the dataset (Table 1 ).

The classification trees predicted whether or not an athlete competed in the NCAA Division I National Cross Country Championships with balanced accuracies of $70.4 \%$ for females and $63.7 \%$ for males (Table 2). Similarly, $\mathrm{k}$ scores were 0.27 for females and 0.20 for males, indicating fair and slight agreement (Cohen, 1960; Landis \& Koch, 1977). The classification trees for the NCAA Division I National Cross Country Championships display the differences in the likelihood of qualifying from different times in U.S. high school track \& field events (Figure 1). From the random forest analyses, the $1600 \mathrm{~m}$ ranked as the most important predictor variable to qualify for the NCAA Division I National Cross Country Championships followed by the $800 \mathrm{~m}$ and then the $3200 \mathrm{~m}$ for females, and the $3200 \mathrm{~m}$ was most important predictor variable followed by the $1600 \mathrm{~m}$ then the $800 \mathrm{~m}$ for males.

Balanced accuracies of the classification trees constructed for each NCAA outdoor track \& field distance event from each high school track \& field distance event ranged from $60.0 \%$ to $76.6 \%$ (Table 2). Information from these trees was used to determine the likelihoods of qualifying for the NCAA Outdoor Track \& Field Division I Preliminary Round from high school race times (Figures 2 and 3). In some instances, the classification trees yielded no or almost no information about the relationship between times for a certain U.S. high school race distance and NCAA race distance. These dyads were omitted from Table 2 and Figures 2 and 3. The most important variables for predicting both male and female NCAA $800 \mathrm{~m}$ and $1500 \mathrm{~m}$ race performances were the high school $800 \mathrm{~m}$ and $1600 \mathrm{~m}$, respectively. For females, the $1600 \mathrm{~m}$ was the most important for predicting NCAA $5000 \mathrm{~m}$ performance and NCAA $3000 \mathrm{~m}$ steeplechase performance. The $3200 \mathrm{~m}$ was the most important variable for predicting NCAA $10,000 \mathrm{~m}$

Table 1. Mean Times for 48th place in the East/West division.

\begin{tabular}{llcr}
\hline \multicolumn{1}{c}{ Event } & East & West \\
\hline Female & $800 \mathrm{~m}$ & $2: 07( \pm 0.4 \mathrm{~s}, 0.003 \mathrm{~s}), 12.4 \%$ & $2: 08( \pm 0.4 \mathrm{~s}, 0.003 \mathrm{~s}), 13.3 \%$ \\
& $1500 \mathrm{~m}$ & $4: 22( \pm 1.1 \mathrm{~s}, 0.004 \mathrm{~s}), 13.9 \%$ & $4: 23( \pm 1.2 \mathrm{~s}, 0.005 \mathrm{~s}), 14.3 \%$ \\
& $5000 \mathrm{~m}$ & $16: 25( \pm 5.3 \mathrm{~s}, 0.005 \mathrm{~s}), 15.7 \%$ & $16: 26( \pm 4.4 \mathrm{~s}, 0.004 \mathrm{~s}), 15.9 \%$ \\
& $10000 \mathrm{~m}$ & $35: 03( \pm 21.9 \mathrm{~s}, 0.010 \mathrm{~s}), 19.7 \%$ & $35: 01( \pm 14.5 \mathrm{~s}, 0.007 \mathrm{~s}), 19.6 \%$ \\
Male & $3000 \mathrm{~m}$ Steeplechase & $10: 35( \pm 8.7 \mathrm{~s}, 0.013 \mathrm{~s}), 19.4 \%$ & $10: 36( \pm 4.7 \mathrm{~s}, 0.007 \mathrm{~s}), 19.5 \%$ \\
& & & $1: 49( \pm 0.5 \mathrm{~s}, 0.005 \mathrm{~s}), 7.9 \%$ \\
& $1500 \mathrm{~m}$ & $1: 49( \pm 0.5 \mathrm{~s}, 0.005 \mathrm{~s}), 7.9 \%$ & $3: 44( \pm 0.5 \mathrm{~s}, 0.002 \mathrm{~s}), 8.7 \%$ \\
& $5000 \mathrm{~m}$ & $3: 45( \pm 0.9 \mathrm{~s}, 0.004 \mathrm{~s}), 9.2 \%$ & $14: 01( \pm 2.4 \mathrm{~s}, 0.003 \mathrm{~s}), 11.1 \%$ \\
& $10000 \mathrm{~m}$ & $14: 06( \pm 2.2 \mathrm{~s}, 0.003 \mathrm{~s}), 11.8 \%$ & $29: 40( \pm 6.7 \mathrm{~s}, 0.004 \mathrm{~s}), 12.9 \%$ \\
& $3000 \mathrm{~m}$ Steeplechase & $29: 46( \pm 3.4 \mathrm{~s}, 0.002 \mathrm{~s}), 13.3 \%$ & $9: 01( \pm 1.9 \mathrm{~s}, 0.004 \mathrm{~s}), 14.4 \%$ \\
\hline
\end{tabular}

The runners with a top 48 time in each event qualify for the East/West NCAA Outdoor Track \& Field Division I Preliminary Round. Data are from 2010 through 2016 and were obtained from www.tfrrs.org. Standard deviations followed by coefficients of variation are in parentheses, and percent differences from world record times as of November 2017 are in italics. World record times were retrieved from www.track\&fieldnews.com 
Table 2. (a) Accuracies of classification trees, females. (b) Accuracies of classification trees, males.

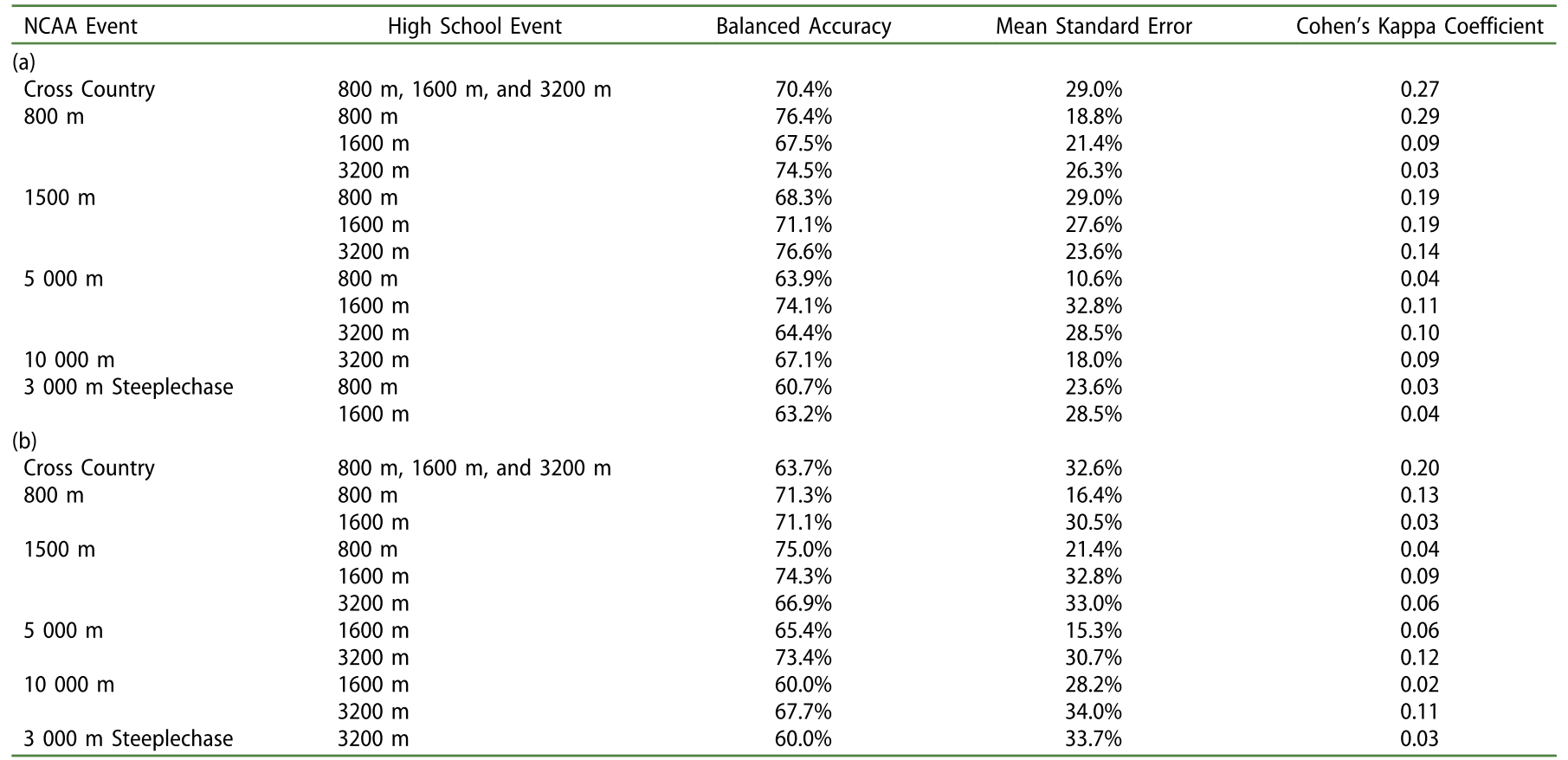

The accuracies of the recursive partitioning algorithms in conditional inference frameworks are presented. As only a small subset of the athletes qualified for the NCAA National Cross Country and East/West NCAA Outdoor Track \& Field Division I Preliminary Round meets, balanced accuracies to account for the imbalance in the dataset are presented.

performance for both males and females as well as NCAA $3000 \mathrm{~m}$ steeplechase and $5000 \mathrm{~m}$ performances for males.

\section{Discussion}

Recruiting distance runners for NCAA cross country/track \& field teams has evolved substantially in the past couple decades, and coaches have begun to allocate larger portions of their team budgets to recruiting expenses (Judson, James, \& Aurand, 2004). This study investigated the relationship between distance running race performance at the high school and collegiate levels in the United States using classification tree modeling. The estimates generated from the models in this study provide a statistically robust and simple method for screening prospective student-athletes based on their high school race performances, and these methods can be applied to address similar research questions for different datasets.

The classification tree models varied in their predictive abilities. The models produced the most reliable estimates for predicting qualifiers in cross country $(70.4 \%)$, the $1500 \mathrm{~m}$ $(63.9-76.6 \%)$, and the $800 \mathrm{~m}(67.5-76.4 \%)$ for females and cross country $(63.7 \%)$, the $5000 \mathrm{~m}(65.4-73.4 \%)$, and the $800 \mathrm{~m}$ (71.3-75.0\%) for males. They produced the least reliable estimates for the $3000 \mathrm{~m}$ steeplechase for both males (60.0\%) and females (60.7-63.2\%). Steeplechase requires a unique set of physiological and biomechanic demands from the athlete that are not necessary in the other distance events (Gabrielli, Fulle, Fanò-lllic, \& Pietrangelo, 2015). Thus, the relative difficulty in predicting the performance of an athlete in this event from other distance events comes at no surprise.
For males, the $3200 \mathrm{~m}$ had the greatest importance for predicting NCAA cross country performance, which seems logical given that it is the high school track \& field race closest in distance to a cross country race. Interestingly, the $1600 \mathrm{~m}$ best predicted NCAA cross country race performance for females. Similarly, the most important variable for predicting race performance in the NCAA $5000 \mathrm{~m}$ for females was the $1600 \mathrm{~m}$ but for males was the $3200 \mathrm{~m}$. The number of observations for the $1600 \mathrm{~m}$ and $3200 \mathrm{~m}$ are equal, suggesting that these results are not an artifact of model bias but arise from some physiological or behavioural difference between male and female runners. Possible reasons for these results include 1) females display greater variance in the ability to sustain maximal volume of oxygen consumption $\left(\mathrm{V}_{2} \mathrm{O}_{\max }\right)$ than males (Davies \& Thompson, 1979); 2) a greater number of females participated in NCAA Division I track \& field while more males competed in high school track \& field (Deaner, 2006), which could lead to greater event specialization for males than females; 3 ) females competing in the $3200 \mathrm{~m}$ compared the $1600 \mathrm{~m}$ and compared to males are more likely to experience symptoms of the female athlete triad (deficiencies in nutrient availability, menstrual function, and bone density) because success in the $3200 \mathrm{~m}$ emphasizes leanness to a greater degree and is associated with higher mileage training than the $1600 \mathrm{~m}$, key factors leading to the female athlete triad (summarized by Louncks, Manore, Sanborn, Sundgot-Borgen, \& Warren, 2007; Wilmore, 1991); 4) some combination of these hypotheses; or 5) none of these. Future research should further explore these hypotheses.

Lynch, Thomas, and Gibson (2016) found that baseline ability contributes most strongly to race times in the $100 \mathrm{~m}$, $200 \mathrm{~m}$, and $400 \mathrm{~m}$ for both males and females in grade twelve. Other variables in their model included the U.S. state or Canada province of residency, specific and general race 


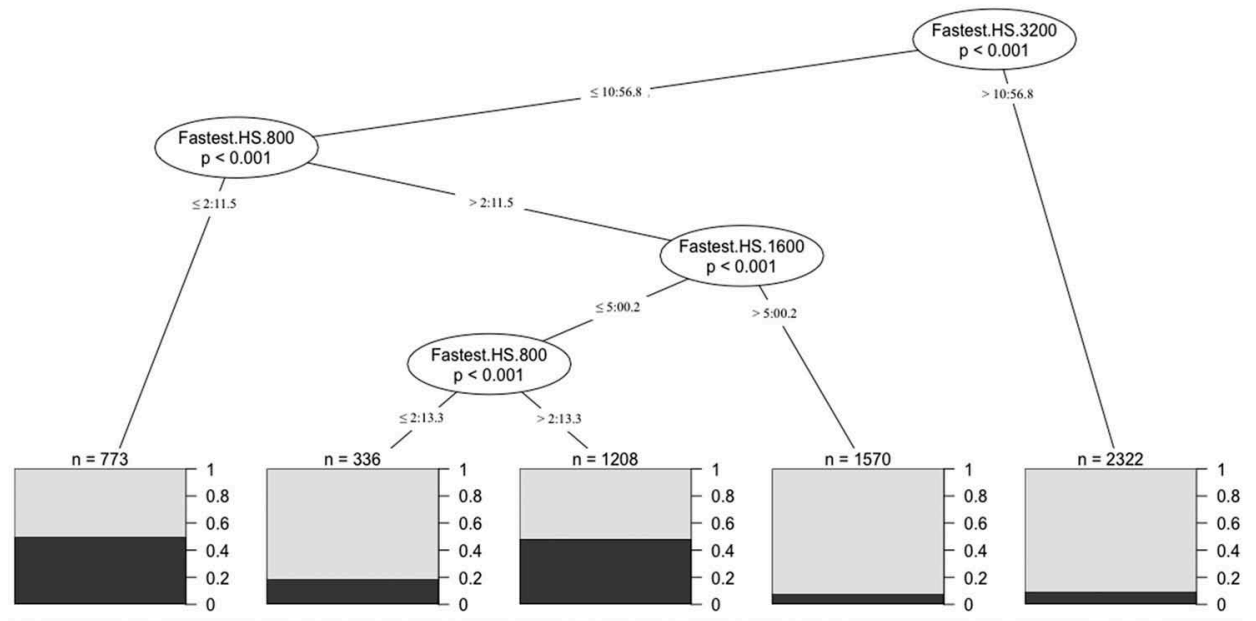

b

Males NCAA Cross Country

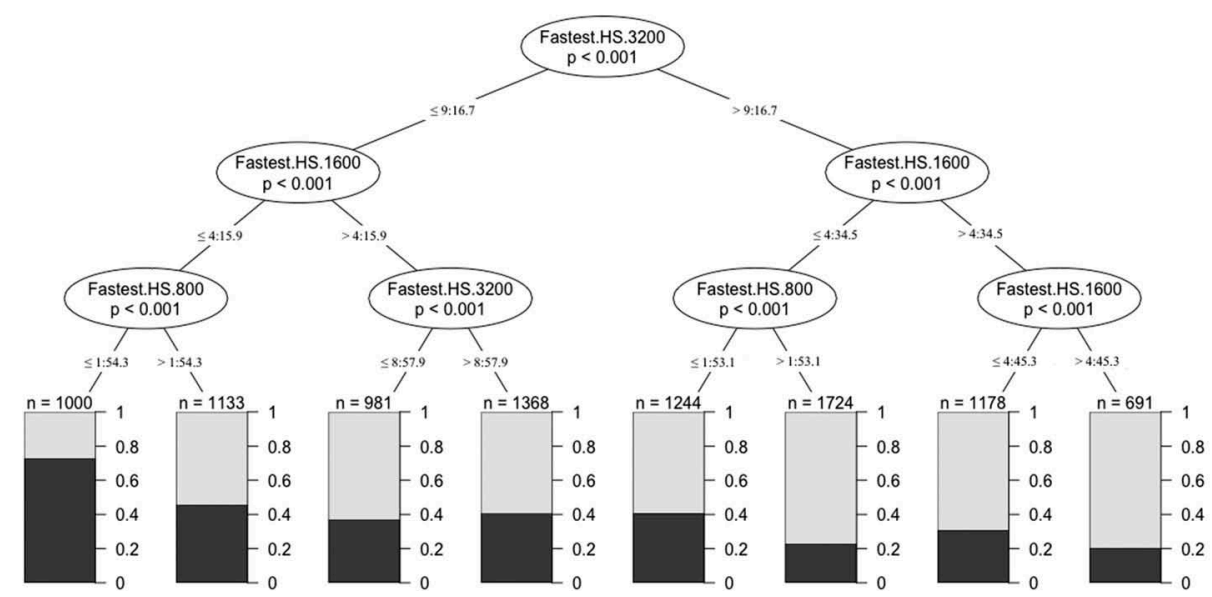

Figure 1. Classification trees to predict the likelihood of qualifying for the NCAA Division I National Cross Country Championships from high school race times in the $800 \mathrm{~m}$, $1600 \mathrm{~m}$, and $3200 \mathrm{~m}$ for females (a) and males (b). Displayed $P$-values are from permutation significance tests at each node, or split in the tree. The shaded regions of the terminal nodes indicate the proportion of individuals who qualified to the NCAA Division I National Cross Country Championships for the given time ranges.

experience, and training exposure. If distance runners follow a similar pattern, it would stand to reason that the race times used as predictor variables in the current study mostly represent baseline ability with some of the variance in high school race performances accounted for by variation in the quality of high school training. The degree to which a runner can improve past his/her baseline with higher levels of training likely varies among individuals and might covary with baseline ability (i.e., those with lower baseline abilities might see greater magnitudes of improvement with the same increase in training as those with higher baseline abilities).

The fastest high school race times typically had the highest likelihood of qualifying to the East/West NCAA Outdoor Track \& Field Division I Preliminary Round. However, slower times occasionally yielded higher likelihoods of qualifying than some faster times. For example, females running between 5:13 and 5:25 in the $1600 \mathrm{~m}$ had a higher likelihood of qualifying for the NCAA Division I $1500 \mathrm{~m}$ Preliminary Round than those running times between 5:00 and 5:12. Only five percent of the athletes in the dataset who competed in both the $1600 \mathrm{~m}$ in high school and the $1500 \mathrm{~m}$ at the NCAA level ran times ranging from 5:13 to 5:25, suggesting that as high school times become increasingly slower, the positive and negative effects imposed by variables not included in the model become stronger. Thus, coaches would benefit from fully exploring the athletic histories of prospective student-athletes, including injuries, previous training, maturation (Rees et al., 2016), and participation in multiple sports (Vaeyens et al., 2009), especially those running slower times because these athletes appear to be more sensitive to these variables not captured by the classification tree models.

The dataset is not appropriate for fitting to a mixed effects model (because of the large number of missing values), but it is probable that individual heterogeneity influences NCAA race performance. Standard errors as large as $49 \%$ associated with the estimated likelihoods of qualifying for the East/West NCAA Outdoor Track \& Field Division I Preliminary Round illustrate this concept. Additionally, the highest balanced accuracy obtained for any model was $76.6 \%$ for females and $75.0 \%$ for males, and the greatest $\mathrm{k}$ were 0.29 and 0.20 for males. Herda et al. (2009) found similar results in that recruiting rankings, while an important contributor, could only explain $3-45 \%$ of college 

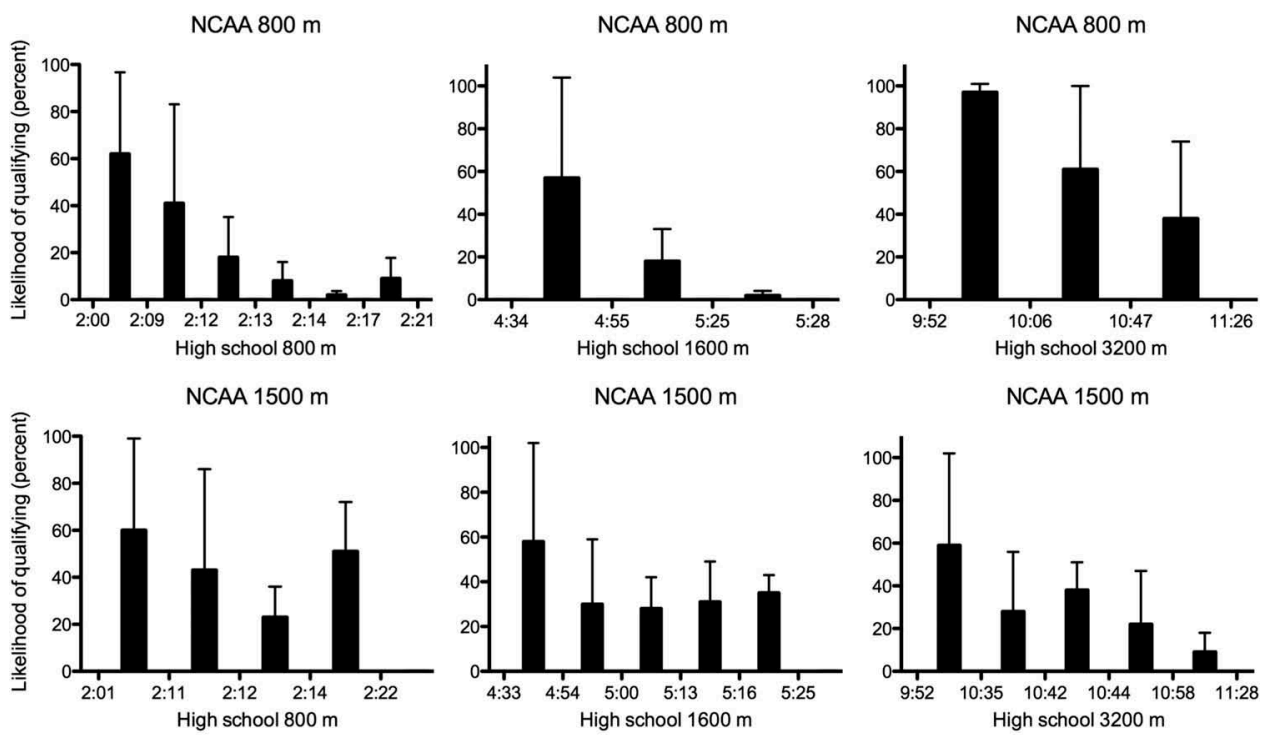

NCAA $1500 \mathrm{~m}$

NCAA $1500 \mathrm{~m}$
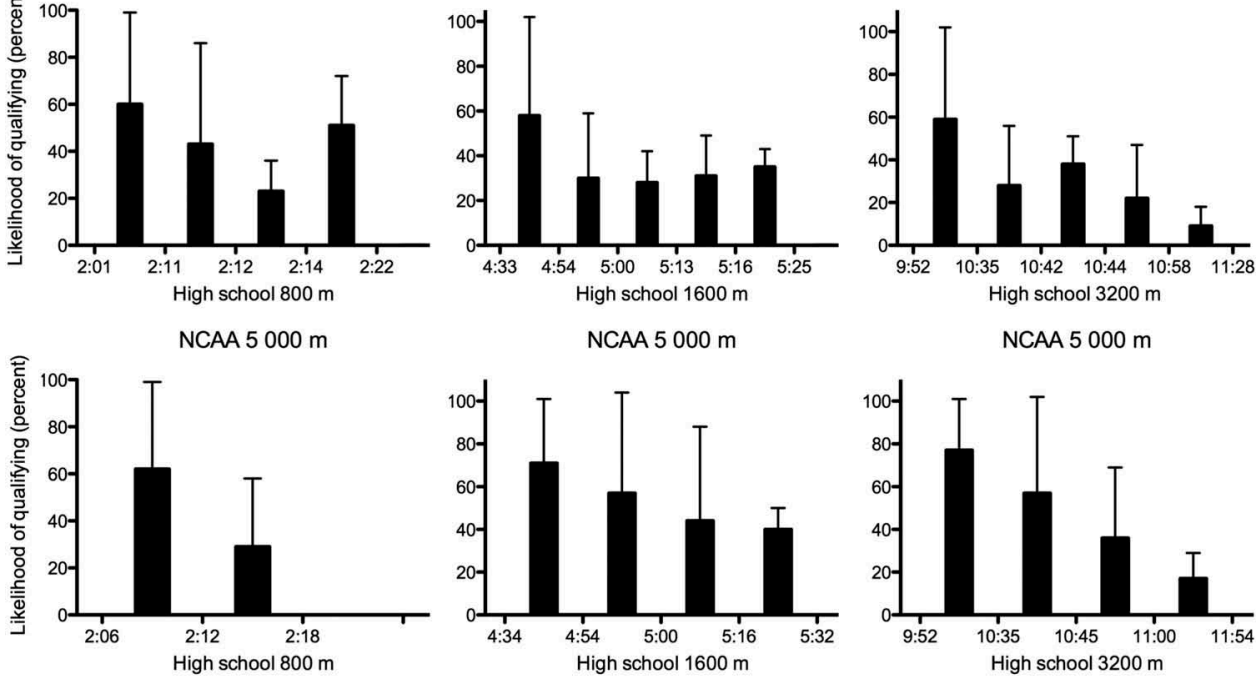

NCAA $5000 \mathrm{~m}$
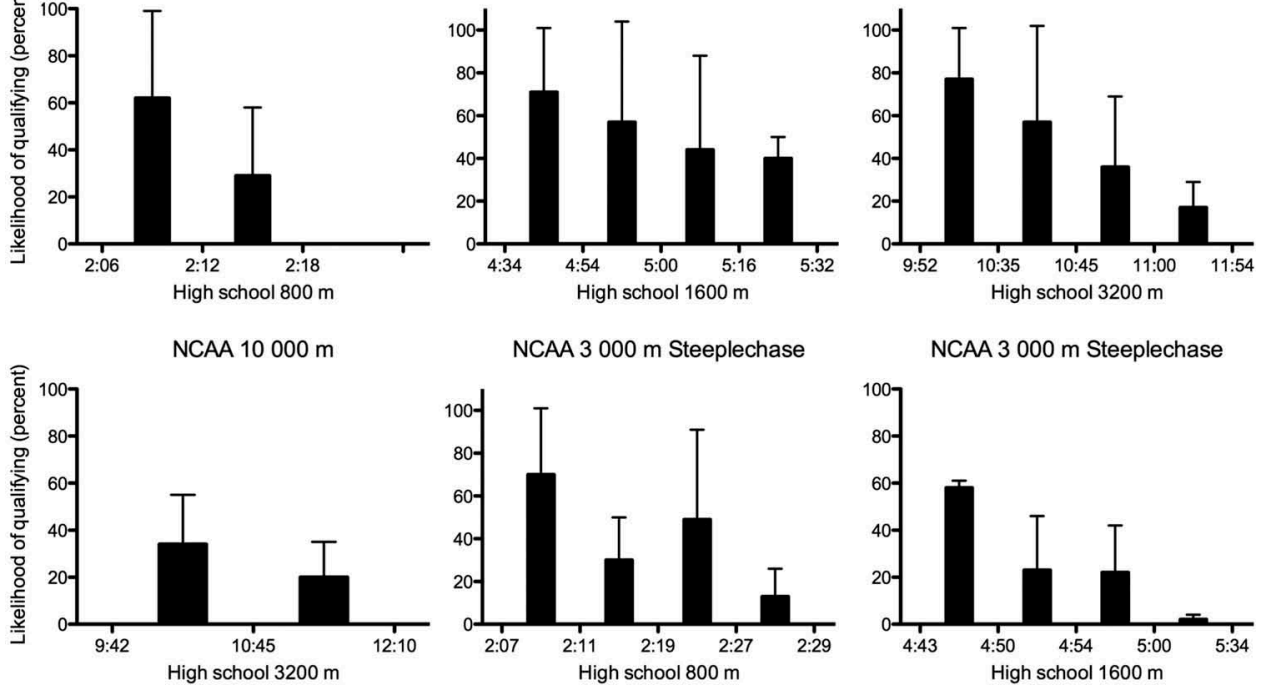

NCAA 3000 m Steeplechase

NCAA 3000 m Steeplechase
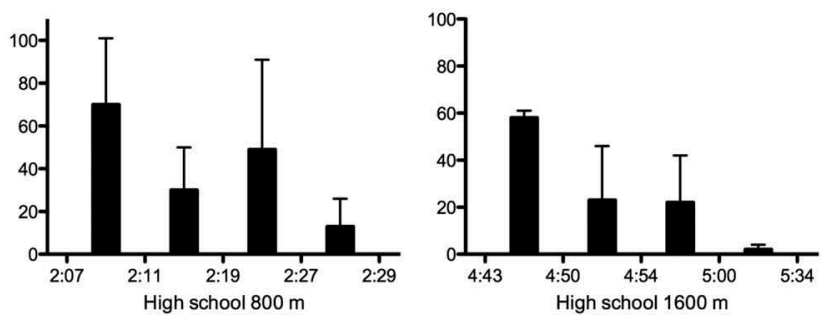

Figure 2. Likelihood of females qualifying for the NCAA Outdoor Track \& Field Division I Preliminary Round for each NCAA outdoor track \& field distance event. Likelihood estimates were determined from building separate classification trees for each NCAA outdoor track \& field distance event coupled with the high school $800 \mathrm{~m}, 1600 \mathrm{~m}$, and $3200 \mathrm{~m}$.

performance for American football. Physical and psychological variables that were not included in the models might contribute to race performance at the NCAA level. Specific factors affecting this individual heterogeneity include predisposition to injury, intrinsic motivation, self-confidence, pressure to perform well, and changes in coaching staff, which are all known to affect competitive performance at the NCAA level (Goose \& Winter, 2012; Marx, Huffmon, \& Doyle, 2008; Wooten, 1994). Training status of a high school runner also affects how much he/she can improve with increased training in college. For example, untrained runners are more likely to make strong improvements in running economy than trained runners (Saunders, Pyne, Telford, \& Hawley, 2004). NCAA Division I cross country runners typically race twice per month versus racing one to three times per week in high school. This change in race frequency enables collegiate runners to endure training with greater rigor, such as higher mileage (Brenner, 2007; Deaner, Lowen, Rogers, \& Saksa, 2015). However, increases in training volume can lead to an increased risk of injury (DiFiori et al., 2014). Injuries and eating disorders are prevalent in female distance runners at the Division I level (Rauh, Margherita, Rice, Koepsell, \& Rivara, 2000; Tenforde et al., 2009; Thompson, Smith, \& DiGioacchino, 2004) and might play a role in inhibiting NCAA race performance relative to high school performance.

Although several dominant high school distance runners maintain their high level of competitiveness in college, many high performing distance runners do not find their stride until they compete at the NCAA level. This notion can be illustrated by the pattern of decreasing but non-zero probabilities of qualifying to the East or West NCAA Division I Outdoor Track \& Field Preliminary Round with slower high school times. Although the conditional inference tree models provide predictive ability, estimates could be strengthened with the inclusion of physical and psychological variables described earlier, and coaches should consider how a distance runner might adjust both physically and psychologically to the university 

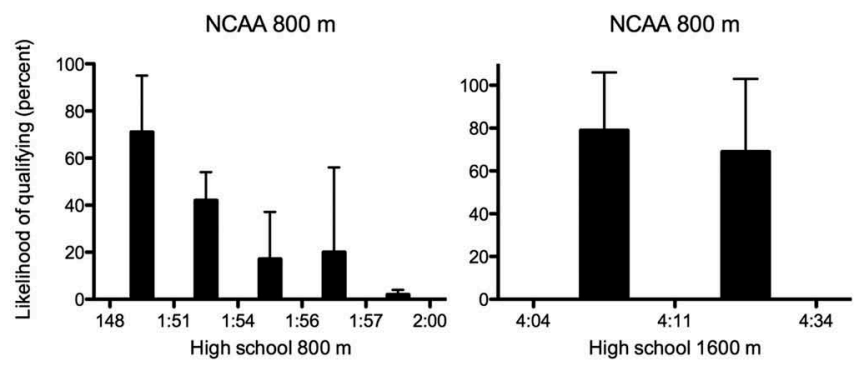

NCAA 3000 m Steeplechase
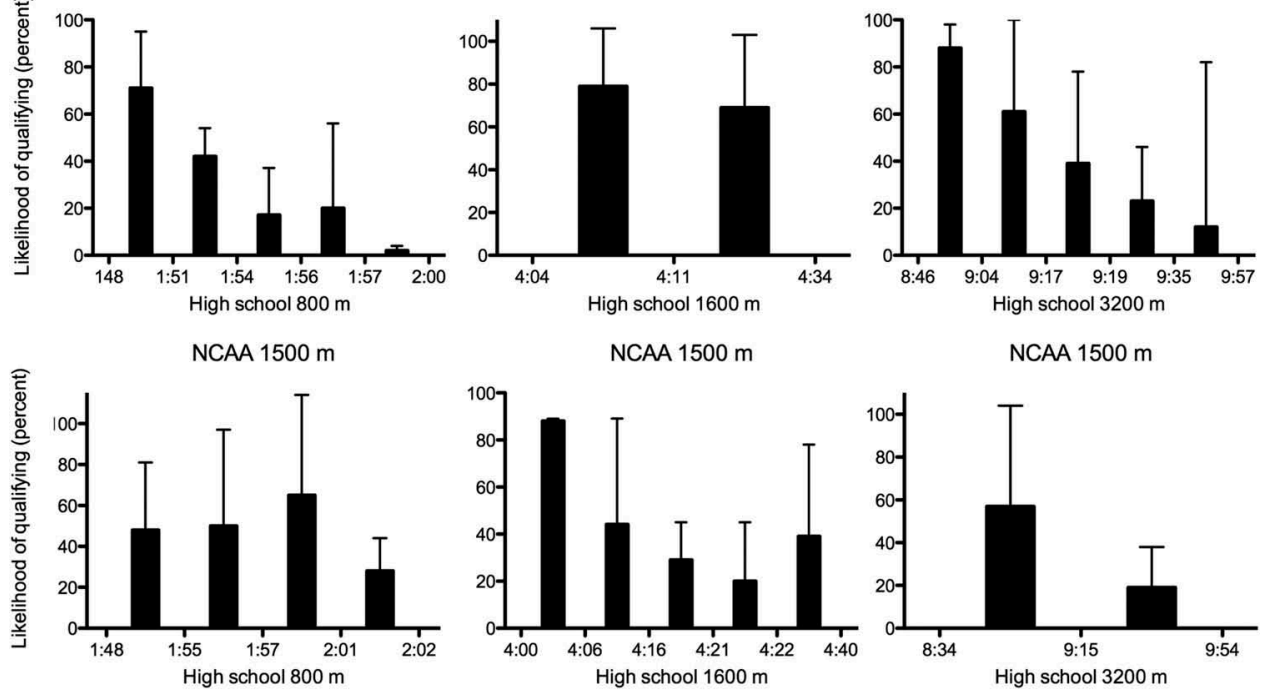

NCAA $5000 \mathrm{~m}$
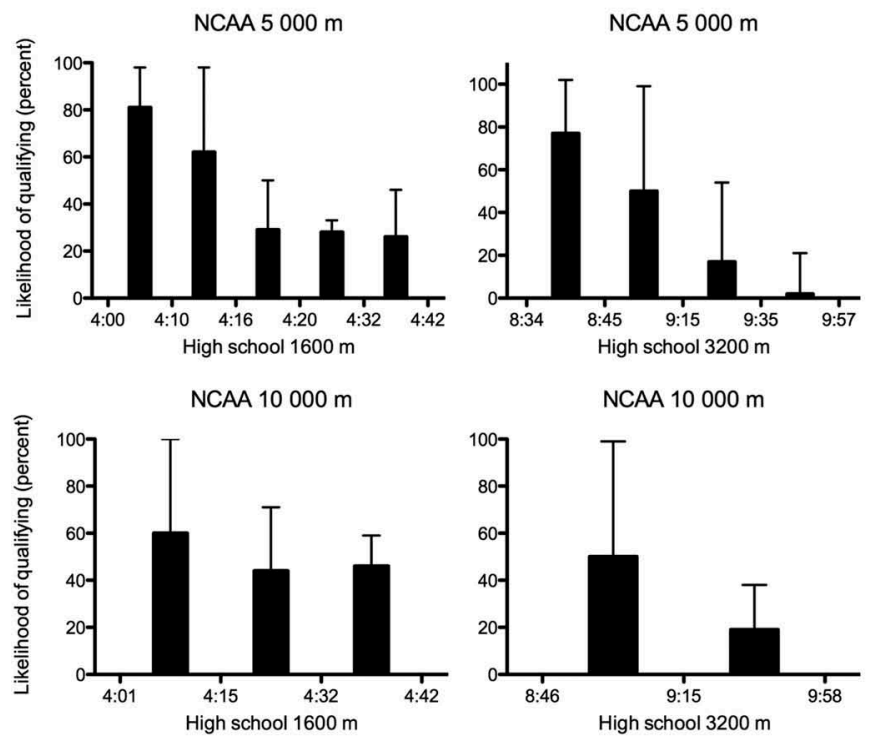

Figure 3. Likelihood of males qualifying for the NCAA Outdoor Track \& Field Division I Preliminary Round for each NCAA outdoor track \& field distance event. Likelihood estimates were determined from building separate classification trees for each NCAA outdoor track \& field distance event coupled with the high school $800 \mathrm{~m}, 1600 \mathrm{~m}$, and $3200 \mathrm{~m}$.

environment. This study provides a more complete understanding of the relationship between race performance at the U.S. high school and NCAA levels as well as guidelines for assessing the risk of recruiting runners who have run specific times in high school for the $800 \mathrm{~m}, 1600 \mathrm{~m}$, and $3200 \mathrm{~m}$. Applying these guidelines to recruiting, NCAA coaches can make more informed decisions for which athletes to further evaluate. Additionally, future studies can apply the methodology of this research to use previous race data to predict race performances set at different metrics, such as national meets in other countries or Olympic qualifications.

\section{Acknowledgments}

The author wishes to thank J. Liu, L. Brusa, J. Scupin, and P. Hutchins for their assistance with compiling and condensing data. P. Hutchins and three anonymous reviewers provided valuable feedback for earlier versions of this manuscript.

\section{Disclosure statement}

No potential conflict of interest was reported by the author.

\section{References}

Barreiros, A., Côté, J., \& Fonesca, A. M. (2014). From early to adult sport success: Analyzing athletes' progression in national squads. European Journal of Sport Science, 14, 178-182.

Brenner, J. S. (2007). Overuse injuries, overtraining, and burnout in child and adolescent athletes. Pediatrics, 119(6), 1242-1245.

Brodersen, K. H., Ong, C. S., Stephan, K. E., \& Buhmann, J. M. (2010). The balanced accuracy and its posterior distribution. Proceedings of the 20th international conference on pattern recognition (pp. 3121-3124). IEEE computer society. doi:10.1109/ICPR.2010.764

Bussman, G., \& Alfermann, D. (1994). Drop-out and the female athlete: A study with track-and-field athletes. In D. Hackfort (Ed.), Psycho-social issues and interventions in elite sport (pp. 89-128). Frankfurt: Lang.

Caro, C. A. (2012). College football success: The relationship between recruiting and winning. International Journal of Sports \& Coaching, 7, 139-152. 
Cohen, J. (1960). A coefficient of agreement for nominal scales. Educational and Psychological Measurement, 20, 37-46.

Davies, C. T. M., \& Thompson, M. W. (1979). Aerobic performance of female marathon and male ultramarathon athletes. European Journal of Applied Physiology and Occupational Physiology, 41, 233-245.

De'ath, G., \& Fabricius, K. E. (2000). Classification and regression trees: A powerful yet simple technique for ecological data analysis. Ecology, 81, 3178-3192.

Deaner, R. O. (2006). More males run fast a stable sex difference in competitiveness in U.S. distance runners. Evolution and Human Behavior, 27, 63-84.

Deaner, R. O., Lowen, A., Rogers, W., \& Saksa, E. (2015). Does the sex difference in competitiveness decrease in selective sub-populations? A test with intercollegiate distance runners. PeerJ, 3, e884.

Depken, C. A., \& Haglund, L. E. (2011). Peer effects in team sports: Empirical evidence from NCAA relay teams. Journal of Sports Economics, 12, 3-19.

DiFiori, J. P., Benjamin, H. J., Brenner, J. S., Gregory, A., Jayanthi, N., Landry, G., \& Luke, A. (2014). Overuse injuries and burnout in youth sports: A position statement from the American Medical Society for Sports Medicine. British Journal of Sports Medicine, 48, 287-288.

Gabrielli, E., Fulle, S., Fanò-Illic, G., \& Pietrangelo, T. (2015). Analysis of training load and competition during the PhD course of a 3000-m steeplechase female master athlete: An autobiography. European Journal of Translational Myology, 25, 195-202.

García, V., Mollineda, R. A., \& Sánchez, J. S. (2009). Index of balanced accuracy: A performance measure for skewed class distributions. In Proceedings of the Fourth IbPRIA, Póvoa de Varzim, Portugal (pp. 441-448). Heidelberg: Springer.

Geisser, S. (1975). The predictive sample reuse method with applications. Journal of the American Statistical Association, 70(350), 320-328.

Goose, M., \& Winter, S. (2012). The coach's impact on long distance runners' training and competition motivation. International Journal of Sports Science \& Coaching, 7, 383-398.

Herda, T. J., Ryan, E. D., DeFreitas, J. M., Costa, P. B., Walter, A. A., Hodge, K. M., ... Cramer, J. T. (2009). Can recruiting rankings predict the success of NCAA Division I football teams? An examination of the relationships among rivals and scouts recruiting rankings and Jeff Sagarin end-ofseason ratings in collegiate football. Journal of Quanitative Analysis in Sports, $5,4$.

Hothorn, T., Hornik, K., \& Zeileis, A. (2006). Unbiased recursive partitioning: A conditional inference framework. Journal of Computational and Graphical Statistics, 15, 651-674.

Hothorn, T., \& Zeileis, A. (2015). Partykit: A modular toolkit for recursive partytioning in R. Journal of Machine Learning Research, 16, 3905-3909. Retrieved from http://www.jmlr.org

Humphreys, B. R., Paul, R. J., \& Weinbach, A. P. (2016). Performance expectations and the tenure of head coaches: Evidence from NCAA football. Research in Economics, 70, 482-492.

Judson, K. M., James, J. D., \& Aurand, T. W. (2004). Marketing the university to student-athletes: Understanding university selection criteria. Journal of Marketing Higher Education, 14, 23-40.

Kelly, B. C., \& Baghurst, T. (2009). Development of the coaching issues survey (CIS). The Sport Psychologist, 23, 367-387.

Kuhn, M. (2016). Caret: classification and regression training. Contributions from Wing, J., Weston, S., Williams, A., Keefer, C., Engelhardt, A., Cooper, T., Mayer, Z., and the R Core Team. Retrieved from http://CRAN.Rproject.org/package=caret. $\mathrm{R}$ package version $6.0-73$
Landis, J. R., \& Koch, G. G. (1977). The measurement of observer agreement for categorical data. Biometrics, 33, 159-174.

Langelett, G. (2003). The relationship between recruiting and team performance in Division 1A college football. Journal of Sports Economics, 4, 240-245.

Louncks, A. B., Manore, M. M., Sanborn, C. F., Sundgot-Borgen, J., \& Warren, M. P. (2007). The female athlete triad. Medicine \& Science in Sports \& Exercise, 39, 1867-1882.

Lynch, K. E., Thomas, A., \& Gibson, B. (2016). Baseline ability makes a larger contribution to race performance in higher school sprinters than race experience or training exposure. Pediatric Exercise Science, 28(4), 565-571.

Marx, J., Huffmon, S., \& Doyle, A. (2008). The student-athlete model and the socialization of intercollegiate athletes. Athletic Insight, 10(1). Retrieved from http://www.athleticinsight.com/Vol10lss1/ StudentAthleteModel.htm

Meinhausen, N. (2006). Quantile regression forests. Journal of Machine Learning Research, 7, 983-999.

NCAA Division I Manual. (2014-2015). Indianapolis, Indiana: National Collegiate Athletic Association. Retrieved from https://www.ncaapubli cations.com/productdownloads/D115.pdf

R Core Team. (2016). R: A language and environment for statistical computing. R Foundation for Statistical Computing, Vienna, Austria. Retrieved from http://www.R-project.org/.

Rauh, M. J., Margherita, A. J., Rice, S. G., Koepsell, T. D., \& Rivara, F. P. (2000). High school cross country running injuries: A longitudinal study. Clinical Journal of Sport Medicine, 10, 110-116. Retrieved from http:// journals.lww.com

Rees, T., Hardy, L., Güllich, A., Abernethy, B., Côté, J., Woodman, T., ... Warr, C. (2016). The great British medalists project: A review of current knowledge on the development of the world's best sporting talent. Sports Medicine, 46, 1041-1058.

Saunders, P. U., Pyne, D. B., Telford, R. D., \& Hawley, J. A. (2004). Factors affecting running economy in trained distance runners. Sports Medicine, $34,465-485$.

Stone, M. (1974). Cross-validatory choice and assessment of statistical predictions. Journal of the Royal Statistical Society B, 36, 111-147.

Strobl, C., Boulesteix, A., Zeileis, A., \& Hothorn, T. (2007). Bias in random forest variable importance measures: Illustrations, sources and a solution. BMC Bioinformatics, 8, 25.

Tenforde, A. S., Sayres, L. C., McCurdy, M. L., Collado, H., Sainani, K. L., \& Fredericson, M. (2009). Overuse injuries in high school runners: Lifetime prevalence and prevention strategies. Pm\&R, 3, 125-131.

Thompson, S. H., Smith, P., \& DiGioacchino, R. (2004). Performance-related injuries and exercise orientation of National Collegiate Athletic Association Division I, II, and III female collegiate cross country runners. Women in Sport \& Physical Activity Journal, 13, 17-26.

Treadway, D. C., Adams, G., Hanes, T. J., Perrewé, P. L., Magnusen, M. J., \& Ferris, G. R. (2012). The roles of recruiter political skill and performance resource leveraging in NCAA football recruitment effectiveness. Journal of Management, 40, 1607-1626.

Vaeyens, R., Güllich, A., Warr, C. R., \& Philippaerts, R. (2009). Talent identification and promotion programmes of Olympic athletes. Journal of Sports Sciences, 27, 1367-1380.

Wilmore, H. J. (1991). Eating and weight disorders in the female athlete. International Journal of Sport Nutrition, 1, 104-117.

Wooten, H. R. (1994). Cutting losses for student-athletes in transition: An integrative transition model. Journal of Employment Counseling, 31, 2-9. 